\title{
The Application Analysis of Computer Technology in Enterprise's Culture Construction
}

\author{
Hairong Zeng ${ }^{1, a}$, Yun Song ${ }^{2, b}$ and Yan Zhou ${ }^{3, c}$ \\ Qingdao Huanghai University, Qingdao, Shangdong, China \\ a24176040@qq.com, b155152036@qq.com, ${ }^{\mathrm{c}} 1452681465 @ q q . c o m$
}

Keywords: Computer technology, Enterprise culture, Application.

\begin{abstract}
Enterprise culture plays an important role in the process of the corporate development. Enterprises are beginning to pay more attention on information technology application in culture constructions. In this paper, the current situation and problems of computer application is analyzed, especially network technology. And the strategy of improving network applications in the enterprise culture construction was studied. A $\mathrm{s}$ a result, the application of computer technology has a positive effect in the construction of enterprise culture. It can save time and effort. It can get twice the result with half the effort, especially in the aspect of corporate identity, employee internal cohesion, learning ability and the enterprise image.
\end{abstract}

\section{Introduction}

Enterprise culture Consists of a core spirit and values. It help employees to strengthen their superiority of enterprise, to enhance the enthusiasm of employees, to improve the work efficiency .It help enterprise to enhance the cohesive affinity of the enterprise internal organization and to strengthen the enterprise vigor.

\section{Importance of Enterprise Culture Construction}

\section{Enterprise Culture has been Cohesive.}

Corporate culture can put employees tightly together and form a strong centripetal force. It make the staff united to move in tandem. It make employees to strive for the realization of the goal. In fact, the enterprise staff's cohesive force is based on the clear goals of the enterprise. The cohesion of enterprise culture come from the fundamental goal of correct choice. If the goals of the enterprise is in the interests of the enterprise, and conforms to the vast majority of the interests of the individual, It is a collective and individual win-win goal. So the foundation of the interests of producing the enterprise cohesion will have. Otherwise, no matter whatever the strategy, the formation of enterprise cohesion are only an illusion.

\section{Corporate Culture has a Gravitational Pull.}

Excellent enterprise culture, not just to staff has the very strong attraction, for partners such as clients, suppliers, customers and the public has very big gravity; The excellent enterprise culture plays a big role to stabilize talents and to attract talents. So also the same partners, if the same conditions, no one don't want to go to a better company to work; No one customer is not willing to cooperate with better business. This is the gravitational pull of enterprise culture.

\section{Enterprise Culture has the Guiding Role.}

The corporate culture is like an invisible baton. It let staff to do anything consciously in accordance with the requirements of enterprise. This is the guiding role of enterprise culture. The enterprise core values and spirit of enterprise, playing an invisible guiding function, can provide direction and methods for the enterprise and employees. It let employees follow spontaneously, thus unifying will and vision of enterprises and individuals, so that enterprise development is promoted. 
Excellent enterprise culture plays an motivating and inspiring role for employees. Good work atmosphere let employees enjoy the joy of work. On the contrary, if the intrigue against each other in an enterprise, employees can't enjoy a natural harmony and happiness. it will produce negative psychology. Cultural atmosphere and value orientation which is formed by the enterprise culture is a kind of spirit. It is able to mobilize and inspire the worker's enthusiasm, initiative and creativity. The people's potential wisdom will be evoked, which will make the employees get all-round development and strengthen enterprise's executive ability as a whole.

\section{Corporate Culture has a Constraint Function.}

Corporate culture itself has standard role. Enterprise cultural norms include ethics, behavior standards and specifications. When the enterprise culture rises to a certain height, the specification is generated intangible binding. It lets employees understand what not to do in their actions, and what unable to do. All this is just what the enterprise culture play a consequence of the "soft" constraints. Through these soft constraints, so as to improve the staff's initiative, enthusiasm, initiative and self-discipline. so as to make employees clear meaning and working methods, so as to improve the staff's sense of responsibility.

\section{The Problems Existing in the Computer Technology in Enterprise Culture Construction}

\section{Corporate Identity Feel will adversely Affected.}

The development of network technology makes employees have many characteristics, such as sharing, openness and freedom of life. When employees use the Internet for information exchange, in fact it is the blend and collision of ideas. A new generation of employees have open - mindedness and accept new things relatively fast speed, but they are slightly less than on the distinguish between good and evil or true and false. They are easily deceived by bad information or false information. Mainstream awareness is being hit. Because of the anonymity and openness characteristics of the internet, the employees release some information fearless of the consequences, for expressing inner emotions. For example dissatisfaction with the enterprise or mental confusion or facing frustration. At the same time, to watch and review staff were not a few. They look the network as a important place against authority or let off steam. This phenomenon is easy to affect the good image of the enterprise.

\section{The Ideas is Intensified hat the Other Enterprises are Good.}

At present, the majority of young employees lack of faith, have ideological confusion and can't digest bitter of grass-roots work. But they fail to adopt effective ways to solve in time, so they will spent a lot of time on the Internet. they have no subject consciousness. In this background, competitive enterprises take advantage of the Internet to spread and promote the enterprise value and the cultural concept on the network platform, especially in terms of welfare and employee care. New employees lack of discrimination. They will shake the faith and the superiority of this enterprise as time passes. So enterprise turnover will rise.

\section{The Difficulty of Processing Enterprise Emergency Increases.}

Information transmission range, transmission speed on the network platform increase the difficulty of monitoring for enterprise. A lot of information to identify up is very difficult, especially in the process of dissemination enterprise emergencies and major events. The effect of the traditional processing methods is very limited. It is not conducive to enterprise harmonious environment maintenance. The openness and anonymity of network platform lead to some irresponsible and emotional expression. Some of them fuel. The results are difficult to predict, evaluate and control. This leads to employees' opinion, thoughts of chaos. Enterprise's instability factors greatly improved. According to the survey, more than half of the young workers will use network information to express their ideas when they meet emergencies. In recent years, the incidence of unexpected events has increased. Unhealthy information spread fast. If not to give the correct public opinion guidance in time, This will have adverse consequences. 


\section{The Strategy of Improving Network Applications in the Enterprise Culture Construction.}

\section{Strengthen the Regulation of the Network}

In view of the problems and challenges of network in the enterprise culture construction, enterprises should actively explore and take effective measures to make the active and positive role of network is able to give full play to, referencing to the following specific content.

First of all, Enterprises should Strengthen the Network Control. Enterprises should take effective measures timely to blocked negative and bad information, release authoritative information and guide the network speech to the right direction. At the same time, enterprises should actively carry out the rule of law and responsibility education, enhance employee self-discipline consciousness and create a vivid, lively, healthy online environment; Company should strengthen the awareness of network information and dispose of different information content by different means. For example, in view of the positive content, employees should be encouraged to forward and discussed. For butch bad rumors, enterprise should clarify the facts in time and prevent the spread of false statements and spread. If I found the staff the information such as family life difficult, doubt, should prompt reply, encourage, make them develop the confidence to life and so on. Especially the emergency should pay attention to the correct guidance of public opinion, release authoritative information in the first time, actively interact with employees and avoid conflict to upgrade.

Second, the Precise Location of Network Function. In the process of Management of network construction, enterprises should make scientific planning and positione accurately according to the actual situation of enterprises, not to attend to one thing and lose an othe rand not to overstate. The traditional enterprise rules and regulations are the management of employees' external behavior, such as the late arrival, doing things has nothing to do with the job, etc. The network is the management of employee ideas. In the process of enterprise culture construction, enterprise should correctly handle the investment proportion between traditional mode and network mode. In this way to keep the enterprise culture construction working, to make the network better able to make up for the deficiency of the traditional management way.

Finally, Pay Attention to Improve the Quality of Our Network. Enterprise's official web site represents the point of view and position, which is closely related to the image of the enterprise. Therefore, Enterprise should guarantee the quality of network. This requires enterprises to attach importance to network management, to provide support on funds and personnel. At the same time, Enterprise should strengthen network forms and contents of the audit, control network quality fundamentally. In addition, Enterprise should control the release time of network information. On the basis of considering the staff's work time, enterprise release the corresponding information at the right time. On the basis of not affecting the work of the staff, enterprise should improve the awareness of network information, adjustment and delete inappropriate network information in time and ensure the freshness of network information.

\section{Focus on the Role of Weibo in Enterprise Culture Construction}

First, PayAttention to the Weibo Construction of the Characteristics of the Subject. Enterprise should use more vivid and lively language to establish a weibo from the view of young employees. This can lay solid foundation for the enterprise culture construction. , For example, enterprise can establish characteristics weibo related to employee life, using thought provoking words and beautiful pictures, in order to change enterprise original stereotyped image. At the same time, enterprise may actively carry out rich and colorful cultural activities, for example, encouraging its employees to establish industry association of weibo and promoting communication, to improve employee's comprehensive quality.

Secondly, Set up Weibo Communication Platform. The enterprise should pay attention to the construction of micro blogging platform, interacted with employees positive and share thoughts of employees. Through careful analysis of the employee's speech, enterprise can grasp the ideological 
dynamic staff accurately and handle emergencies. When encountering a network crisis, enterprises should put real information on twitter in the first time, response positively, in order to win trust and control public opinion direction.

Finally, Focus on the Positive Energy. Enterprise's daily operation and management on micro blogging should pay attention to the use of celebrity effect. Namely the unity and strive for more active. be influential in weibo big business elite, encourage the positive energy release information. Especially when network crisis, celebrities who has wined the trust of workers should do a good job of public opinion guide with the enterprise, to guarantee the stability of the overall situation.

\section{Pay Attention to WeChat Role in Enterprise Culture Construction}

First of All, Use WeChat Group to Strengthen Exchanges. Enterprises can establish WeChat group by teams, departments or enterprises. In WeChat group through group discussion, communication, interaction to rich life in the workplace and strengthen the team cohesion. At the same time, because the WeChat information dissemination is not affected by local, national, It is possible to build the cross-sectoral, cross-regional, cross product team. It will widen the channels of accessing information. For example, members obtain some useful information, such as a data themselves, they can shared with other team members. In addition, enterprises should actively strive for the business elite to join WeChat group, encourage them to release positive energy information and encourage them introduce the advantage of this enterprise properly in their own circle of friends. This can increase enterprise's identity to staff.

Second, build learning mechanism under the condition of WeChat public number. When the enterprise has the public number, it can spread corporate culture step by step, fully to every employee. Because of a variety of forms, employees are easy to accept. In recent years, collaborative learning has received great attention by enterprises, which means to achieve learning goals, to use incentive mechanism to encourage and guide the members to participate in the study between mutual cooperation, to complete a common goal. This can improve the learning efficiency. Considering the WeChat is not affected by space and time, it is stability of the collaborative learning. WeChat public number creates a good condition for the realization of collaborative learning and smooth implementation. At the same time, the personnel department should actively participate and give directions in collaborative learning to control and ensure the quality of collaborative learning.

\section{Pay Attention to the Role of Enterprise's Official Website in Enterprise Culture Construction}

Setting up enterprise good image is one of the important task for the construction of enterprise culture, which is the key to enterprise development and survival. especially under the background of the current market competition, the enterprise must implement image creation. It can achieve twice the result with half the effort from the official website construction. Enterprises set up their own official website, then they can actively promote enterprise's core values, excellent team, proud achievements and the public welfare activities through various forms. Such propaganda can not only improve the reputation of enterprises to improve efficiency, also can enhance the staff's superiority and master consciousness. The refer the frequency of employee turnover will reduce. Companies can open a column on employees' interests in the web site, such as social security, to provide convenient for staff to query and consult. Which will make employees feel fair and open, approve the enterprise's service and care.

\section{Conclusion}

The development of computer technology brings opportunities and challenges for the enterprise culture construction. Enterprises can reduce the problem of computer technology through the network regulation. At the same time computer technology can serve the enterprise culture 
construction through weibo, WeChat and enterprise's official web site. So enterprises should attach importance to the application of computer technology.

\section{Acknowledgement}

Innovation and Entrepreneurship EducationProject in Qingdao Huanghai University(Project Number:2016cxcy1)

\section{reference}

[1]X.Q. Yuan. The role of enterprise culture and its construction, J. JiangXi building materials. 2(2012)291-292.

[2]Z.X. Liao. The application of computer technology in enterprise management, J. modern corporate culture, 29(2014)67-68.

[3]W.H. Wei. Analyses the application of new computertechnology in enterprise management, J. economic study Tribune, 13(2012 )23-24. 